\title{
Global Scenario of Malnutrition: A Review
}

\author{
Faizul Hassan Shah* \\ Department of Nutritional Sciences, Institute of Diet and Nutritional Sciences, Pakistan
}

*Corresponding author: Faizul Hassan Shah, Department of Nutritional Sciences, Institute of Diet and Nutritional Sciences, Pakistan.

Received Date: July 15, 2019

Published Date: June 10, 2020

\begin{abstract}
Billions of people in the world are suffering from malnutrition. Malnutrition is widely prevalent in under-develop world especially South Asia and Africa where more than half of the world's malnourished children are found. There are variety of nutritional deficiency outcomes such as stunting, wasting, low birth weight and overweight. Consequently, low productivity, poverty and low standard of living are widespread. This review provides an overview of global scenario of malnutrition.
\end{abstract}

\section{Introduction}

Malnutrition is a pathological state resulting from relative or absolute deficiency of one or more nutrients. It is a physiological imbalance that arises because of non-optimal eating of food as a function of quantity and quality" [1]. Malnutrition is primary when the food is not available or secondary when food is available, but the body cannot assimilate it for one or another reason [2]. Malnutrition resulted in number of diseases characterized by cellular imbalance between nutrients supply and body's demand to ensure good health. Primary malnutrition may be due to poverty, high birth rate, poor lactation, improper knowledge about weaning food, food prohibitions, illiteracy and high maternal deaths. Furthermore, secondary malnutrition is mainly due to malabsorption of nutrients, infections, metabolic disorders and failure to have immunization against deadly diseases [3]. Although, the world has progressed technologically and economically, still in 2016, globally there were 155 million children (age $<5$ years) stunted, 52 million wasted and 41 million overweight. About $50 \%$ of the child deaths around the world are due to the malnutrition. This situation demands united call and efforts to lower human sufferings for quality life [4].

Malnutrition is a global apprehension affecting vulnerable segments of the population i.e. children, pregnant and/or lactating females, old age people and calamity-stricken people. About 795 million people in the world do not have enough food to lead a healthy active life. The vast majority of the world's hungry people live in developing countries, where $12.9 \%$ population is undernourished. Poor nutrition causes nearly half (45\%) of deaths in children under five i.e. 3.1 million children each year. Worldwide, one out of six children are underweight [5]. Approximately, 66 million primary school aged children attend classes hungry across the developing world. It is estimated that about US $\$ 3.2$ billion per year is needed to feed 66 million hungry school aged children under the school nutrition programs initiated by The World Food Program (WFP) [6].

\section{Stunting}

Stunting is defined as the percentage of children (age $<5$ years) whose height for age is below minus two standard deviation's (moderate and severe stunting) and/or minus three standard deviations (severe stunting) from the median of the WHO Child Growth Standards [7]. Growth and development are very critical in the early period of the life especially 0 to 59 months. Worldwide, more than $26 \%$ of the children (age $<5$ years) were stunted in 2011. However, the distribution is not equal in all parts of the world as $75 \%$ of them reside in Africa (40\%) and South Asia (39\%). Fourteen countries are home of about $80 \%$ of the world's stunted children. The countries in order of global burden are; India (38\%), Nigeria (7\%), Pakistan (6\%), China (5\%), Indonesia 
(5\%), Bangladesh (4\%), Ethiopia (3\%), Democratic Republic of the Congo (3\%), Philippines (2\%), United Republic of Tanzania (2\%), Egypt (2\%), Kenya (1\%), Uganda (1\%) and Sudan (1\%) [8]. The prevalence of stunting has reduced about $36 \%$ since 1990 with an average yearly decline of $2.1 \%$. Maximum decline was observed in East Asia and in Pacific regions (70\%). China has worked a lot in the past two decades and set an example to fight against malnutrition by reducing $20 \%$ malnutrition from 1990 to 2010 . However, much work still needs to be done to reduce stunting in sub-Saharan Africa, North Africa, South Asia and Middle East [9].

\section{Wasting}

Wasting is a condition which refers to acute under nutrition. It is defined as the percentage of children (age $<5$ years) whose weight for height is below minus two standard deviations (moderate and severe wasting) and/or minus three standard deviations (severe wasting) from the median of the WHO Child Growth Standards [7(a)]. This is the most devastating condition because it can ultimately lead to the death. Worldwide, 52 million children (age $<5$ years) are moderately or severely wasted. During 1990 to 2011, 11\% decline in wasting was observed globally. The hardest hit segment of the world is South Asia, where approximately $16 \%$ of the children are wasted, which mean that one in six children would have been affected by moderate or severe wasting. India contribute to the burden of wasting more than any other country where 25 million wasted children are living. In Africa, almost 1 in 10 children (age $<5$ years) (9\%) were wasted. Significant correlation was found between the countries having high prevalence of wasting and food insecurity or experiencing climatic emergencies more frequently. The major reasons behind this correlation is more spread of infectious diseases as well as social and cultural limitations [10].

\section{Under weight}

Under weight is a form of malnutrition which includes both the elements of wasting as well as stunting. It is defined as the percentage of children (age $<5$ years) whose weight for age is below minus two standard deviations (moderate and severe underweight) and/or minus three standard deviations (severe underweight) from the median of the WHO Child Growth Standards [7(b)]. Worldwide, almost 101 million children are underweight. The condition is worst in South Asia where 59 million (33\%) underweight children are living followed by Sub-Saharan Africa were the prevalence is more than 30 million (21\%) children. Global indicators have shown $37 \%$ reduction in the last two decades. Maximum decline have been attained by Europe and the independent states of Commonwealth, where it has declined up to $87 \%$ followed by East Asia and the Pacific countries (73\%). Progress in the remaining areas of the world remained slow where it has declined only $26 \%$ [10(a)].

\section{Low birth weight}

Babies having birth weight less than $2.5 \mathrm{~kg}$ are considered as low birth weight children. Globally, more than 20 million infants (15\%) are low birth weight. Approximately, 33\% of these children were born in India making it biggest contributor of this burden. One in four newborns children in South Asian region has low birth weight [11]. Five countries account for more than half of the global low birth weight burden. These countries include India (7.5 million), Pakistan (1.5 million), Nigeria (0.8 million), Bangladesh (0.7 million) and Philippines (0.5 million) [12]. The biggest challenge in estimation is the unavailability of the data. In 2011, almost $50 \%$ of the children were not measured for their birth weight. So, the actual number may be even much higher in the less developed world where even the data collection is a difficult task [13]. Some new methods have been introduced recently to fix this problem of underreporting of birth weight, but the numbers are still likely to be less than the actual. The World Health Assembly has set a new target to reduce low birth weight up to $30 \%$ from 2010 to 2025 , which still looks to be a great challenge [14].

\section{Overweight}

Overweight is defined as the percentage of children (age $<5$ years) whose weight for height is above two standard deviations (overweight and obese) and/or above three standard deviations (obese) from the median of the WHO Child Growth Standards [15]. In the past, overweight was linked merely to developed countries, but the data collected in 2011 by WHO has shown a strange connection of overweight and low to middle income countries where $69 \%$ of the world's overweight reside. Still, $8 \%$ higher prevalence was observed in the developed countries than less developed countries [16]. Worldwide, almost 43 million children (7\% of the world children age $<5$ years) are overweight in 2011 as estimated by WHO [8(a)]. The number has been increased (3\%) from the last two decades in the Africa. Similar increasing trend was reported for the rest of the regions of the world [2(a)].

\section{Conclusion}

Current dietary practices in the developing countries are not enough to cope up the nutritional requirements of the population. The world is facing the problem of double burden of malnutrition i.e. undernutrition as well as overnutrition. There is a great need to develop efficient nutritional strategies to tackle this issue. Moreover, the outcomes deduced from present review is supportive for the researchers, stakeholders and technologists dealing with malnutrition for better understanding of the situation for future planning.

\section{Acknowledgement}

None.

\section{Conflict of interest}

Author declare no conflict of interest.

\section{References}

1. Soeters P, Bozzetti F, Cynober L, Forbes A, Shenkin A, et al. (2017) Defining Malnutrition: A Plea to Rethink. Clin Nutr 36(3): 896-901. 
2. Black RE, Victora CG, Walker SP, Bhutta ZA, Christian P, et al. (2013) Maternal and Child Undernutrition and Overweight in Low-Income and Middle-Income Countries. Lancet 382: 427-451.

3. Vandersmissen L, Peeters A (2015) Correlation Between Nutritional Status and Development of Children Up To 5 Years of Age, Living in Extreme Poverty. Hasselt, Belgium.

4. Victora CG, Onis M, Hallal PC, Blossner M, Shrimpton R (2010) Worldwide Timing of Growth Faltering: Revisiting Implications for Interventions. Pediatrics 125(3): e473-480.

5. Keenan RJ, Reams GA, Achard F, Freitas JV, Grainger A, et al. (2015) Dynamics of global forest area: results from the Food and Agriculture Organization Global Forest Resources Assessment. For Ecol Manag 7: 9-20.

6. Maxwell D, Fitzpatrick M (2012) The 2011 Somalia Famine: Context, Causes and Complications. Global Food Security 1(1): 5-12.

7. De Onis M (2015) World Health Organization Reference Curves. The ECOG's eBook on Child and Adolescent Obesity. Geneva, Switzerland.

8. De Onis M, Blössner M, Borghi E (2012) Prevalence and Trends of Stunting Among Pre-School Children, 1990-2020. Public Health Nutr 15(1): 142-148.

9. (2015) World Bank group joint child malnutrition estimates Key findings of the 2015 edition Levels and trends in child malnutrition. Jointly published by data and analytics section of the division of data, research and policy, UNICEF New York; Department of nutrition for health and development, WHO Geneva; development data group of the world bank, Washington DC, USA.

10. Khobragade AW, Rajan K (2017) Global Hunger Index of India Based on National Family Health Survey-IV with Special Reference to Some States and Critical Review. Int J Comm Med Pub Health 4: 2783-2786.

11. Day KL (2017) Exposure to Overprotective Parenting and Psychopathology in Extremely Low Birth Weight Survivors.

12. Blossner M, Mercedes DO (2005) Malnutrition: Quantifying the Health Impact at National and Local Levels. Geneva, Switzerland.

13. De Onis M, Blossner M, Borghi E, Frongillo EA, Morris R (2004) Estimates of Global Prevalence of Childhood Underweight in 1990 and 2015. JAMA 291(21): 2600-2606

14.WHO (2009) Report on the Global Tobacco Epidemic Implementing Smoke-Free Environments. World Health Organization, Geneva, Switzerland.

15. Seetharaman S, Golden NH, Halpern FB, Peebles R, Carlson JL (2017) Effect of a Prior History of Overweight on Return of Menses in Adolescents with Eating Disorders. J Adolesc Health 60(4): 469-471.

16. De Onis M, Blössner M, Borghi E (2010) Global Prevalence and Trends of Overweight and Obesity Among Preschool Children. Am J Clin Nutr 92(5): 1257-1264. 